\title{
Commentary Inhaled activated protein C: a novel therapy for acute lung injury?
}

\author{
Kathleen D Liu', Mark R Looney² and Michael A Matthay²
}

\begin{abstract}
1'Divisions of Nephrology and Critical Care Medicine, Departments of Medicine and Anesthesia, University of California, San Francisco, San Francisco, CA 94143-0624, USA

${ }^{2}$ Cardiovascular Research Institute and the Division of Pulmonary and Critical Care Medicine, Departments of Medicine and Anesthesia, University of California, San Francisco, San Francisco, CA 94143-0624, USA
\end{abstract}

Corresponding author: Michael A Matthay, michael.matthay@ucsf.edu

Published: 21 May 2009

Critical Care 2009, 13:150 (doi:10.1186/cc7869)

This article is online at http://ccforum.com/content/13/3/150

(C) 2009 BioMed Central Ltd

See related research by Waerhaug et al., http://ccforum.com/content/13/2/R51

\begin{abstract}
Acute lung injury (ALI) is characterized by the presence of dysregulated coagulation and inflammation. Therefore, Waerhaug and colleagues hypothesized that administration of activated protein C (APC) via the inhaled route would be a novel and effective treatment for ALI. They demonstrated that inhaled APC improved oxygenation and lung aeration in a sheep model of lipopolysaccharide-induced ALI, but did not alter lung water or hemodynamics. Future studies are needed to determine plasma and airspace APC levels when administered by the inhaled route, and to determine if inhaled APC has a similar effect in other models of ALI.
\end{abstract}

In the previous issue of Critical Care, Waerhaug and colleagues [1] test the hypothesis that inhaled activated protein $\mathrm{C}$ (APC), a novel therapy approved for the treatment of severe sepsis [2], may be an effective treatment for acute lung injury (ALI). The benefits of APC therapy in sepsis are likely due to its anti-coagulant and anti-inflammatory properties, along with its roles as an anti-apoptotic factor and in the maintenance of endothelial barrier functions [3]. ALI and acute respiratory distress syndrome (ARDS) are a major cause of morbidity and mortality in critically ill patients, with an estimated mortality rate of $25 \%$ to $40 \%$ [4,5]. Although the use of a lung-protective ventilation strategy produced a major breakthrough in supportive care for ALI patients [6], there is still no effective pharmacological therapy for ALI.

Based on human and animal studies demonstrating that pathogenesis of $\mathrm{ALI}$ involves exuberant inflammation and coagulation activation [7-9], APC has been proposed as a treatment for ALI/ARDS. However, systemic APC administration is associated with a modest increase in the risk of bleeding, which can be life-threatening. Thus, Waerhaug and colleagues [1] hypothesized that inhaled aerosolized APC could be effectively delivered to reduce lung injury in a sheep model of lipopolysaccharide (LPS)-induced ALI. These investigators had previously reported that intravenous recombinant APC attenuated LPS and oleic acid-induced lung injury $[10,11]$. Infusion of LPS led to a rapid deterioration in the arterial partial oxygen pressure $\left(\mathrm{PaO}_{2}\right)$ with an associated rise in the alveolar-arterial ( $\mathrm{A}-\mathrm{a})$ difference, and an increase in the intrapulmonary shunt (Qs/Qt). These changes in oxygenation were associated with increased airspace disease on quantitative computed tomography scans. LPS administration also resulted in hemodynamic changes, including increased pulmonary artery pressure, pulmonary artery occlusion pressure, and heart rate, as well as a trend towards decreased mean arterial pressure.

What was the impact of inhaled APC administration on the LPS-induced ALI? While inhaled APC improved oxygenation with an associated decrease in the alveolar-arterial difference and the pulmonary shunt fraction, there was only a modest improvement in lung aeration in APC-treated animals. Improved aeration could only be observed at functional residual capacity, but not at end-inspiration, when the lung is maximally inflated. Further, there was no decrease in lung water in the APC-treated sheep. Inhaled APC had no significant effect on any of the hemodynamic changes observed after LPS administration. The investigators did not observe any bleeding complications associated with inhaled APC therapy.

Thus, Waerhaug and colleagues [1] demonstrate for the first time that APC administered by the inhaled route may have benefit in ALI by improving gas exchange. Given the increase

$\mathrm{ALI}=$ acute lung injury $\mathrm{APC}=$ activated protein $\mathrm{C} ; \mathrm{ARDS}=$ acute respiratory distress syndrome; $\mathrm{LPS}=$ lipopolysaccharide. 
in bleeding complications associated with administration of intravenous APC, the administration by the inhaled route is a novel approach that may allow for safer drug administration. However, there are several limitations with the study that should be noted. First, administration of inhaled APC improved oxygenation as well as lung aeration as assessed by quantitative computed tomography scan. However, neither of these physiological measurements has been shown to correlate with mortality in patients with ALI [12]. The authors did not use formal recruitment maneuvers to assess lung aeration (such as those described by Gattinoni and colleagues [13]), in which patients with a higher percentage of recruitable lung had higher rates of death than patients who had better lung aeration. Second, inhaled APC did not improve the alterations in hemodynamics, and there was no reduction in the quantity of pulmonary edema. However, targeted administration of APC to the distal airspaces might in fact be appealing, because it could allow for attenuation of lung injury without significant systemic effects. Finally, plasma and bronchoalveolar lavage concentrations of APC were not reported by the authors, so it is unknown whether or not significant plasma levels were achieved in this study.

Nonetheless, the present study is an excellent, large animal model-based study of ALI; the novelty of the study is the route of APC administration. Additional studies are warranted to understand the distribution of inhaled APC within the lungs and whether or not this can be further optimized, as well as determination of plasma levels of APC. It will be of interest to see whether inhaled APC has benefit in other models of ALI, given the common pathogenic mechanisms that underlie different types of ALI. We found no therapeutic benefit of intravenous and intra-tracheal APC in a hyperoxic model of $A L I$ in mice [14]. Similarly, we have previously reported in a phase II randomized clinical trial of APC in ALI patients that there was no difference in patient outcomes (ventilator-free days or mortality) with APC administration [15]. However, our patient population was limited to ALI patients without severe sepsis and at low risk of bleeding complications. We hypothesized that one of the reasons that we did not observe a benefit with APC treatment was the low overall mortality (13.5\%) of this patient population. More studies will be needed to test aerosolized APC, especially in animal models of acute bacterial pneumonia.

\section{Competing interests}

The authors declare that they have no competing interests.

\section{Acknowledgements}

KDL was supported by NCRR/OD KL2 RR024130; MRL was supported by NHLBI HL082742; MAM was supported by NHBLI HL51856.

\section{References}

1. Waerhaug K, Kuzkov VV, Kuklin VN, Mortensen R, Nordhus KC, Kirov MY, Bjertnaes LJ: Inhaled aerosolised recombinant human activated protein C ameliorates endotoxin-induced lung injury in anesthetised sheep. Crit Care 2009, 13:R51.
2. Bernard GR, Vincent JL, Laterre PF, LaRosa SP, Dhainaut JF, Lopez-Rodriguez A, Steingrub JS, Garber GE, Helterbrand JD, Ely EW, Fisher CJ Jr; Recombinant human protein C Worldwide Evaluation in Severe Sepsis (PROWESS) study group: Efficacy and safety of recombinant human activated protein $\mathrm{C}$ for severe sepsis. N Engl J Med 2001, 344:699-709.

3. Looney MR, Matthay MA: Bench-to-bedside review: the role of activated protein $C$ in maintaining endothelial tight junction function and its relationship to organ injury. Crit Care 2006, 10:239.

4. Ware LB, Matthay MA: The acute respiratory distress syndrome. N Engl J Med 2000, 342:1334-1349.

5. Rubenfeld GD, Caldwell E, Peabody E, Weaver J, Martin DP, Neff $M$, Stern EJ, Hudson LD: Incidence and outcomes of acute lung injury. N Engl J Med 2005, 353:1685-1693.

6. Network TARDS: Ventilation with lower tidal volumes as compared with traditional tidal volumes for acute lung injury and the acute respiratory distress syndrome. N Engl J Med 2000, 342:1301-1308.

7. McClintock D, Zhuo H, Wickersham N, Matthay MA, Ware LB: Biomarkers of inflammation, coagulation and fibrinolysis predict mortality in acute lung injury. Crit Care 2008, 12:R41.

8. Ware LB, Camerer E, Welty-Wolf K, Schultz MJ, Matthay MA: Bench to bedside: targeting coagulation and fibrinolysis in acute lung injury. Am J Physiol Lung Cell Mol Physiol 2006, 291:L307-311.

9. Ware LB, Matthay MA, Parsons PE, Thompson BT, Januzzi JL, Eisner MD: Pathogenetic and prognostic significance of altered coagulation and fibrinolysis in acute lung injury/acute respiratory distress syndrome. Crit Care Med 2007, 35:18211828.

10. Waerhaug K, Kuklin VN, Kirov MY, Sovershaev MA, Langbakk B, Ingebretsen OC, Ytrehus K, Bjertnaes LJ: Recombinant human activated protein $\mathrm{C}$ attenuates endotoxin-induced lung injury in awake sheep. Crit Care 2008, 12:R104.

11. Waerhaug K, Kirov MY, Kuzkov VV, Kuklin VN, Bjertnaes LJ: Recombinant human activated protein $\mathrm{C}$ ameliorates oleic acid-induced lung injury in awake sheep. Crit Care 2008, 12: R146.

12. Seeley E, McAuley DF, Eisner M, Miletin M, Matthay MA, Kallet $\mathrm{RH}$ : Predictors of mortality in acute lung injury during the era of lung protective ventilation. Thorax 2008, 63:994-998.

13. Gattinoni L, Caironi P, Cressoni M, Chiumello D, Ranieri VM, Quintel M, Russo S, Patroniti N, Cornejo R, Bugedo G: Lung recruitment in patients with the acute respiratory distress syndrome. N Engl J Med 2006, 354:1775-1786.

14. Looney MR, Esmon CT, Matthay MA: Role of coagulation pathways and treatment with activated protein $\mathrm{C}$ in hyperoxic lung injury. Thorax 2009, 64:114-120.

15. Liu KD, Levitt J, Zhuo H, Kallet RH, Brady S, Steingrub J, Tidswell M, Siegel MD, Soto G, Peterson MW, Chesnutt MS, Phillips C, Weinacker A, Thompson BT, Eisner MD, Matthay MA: Randomized clinical trial of activated protein $\mathrm{C}$ for the treatment of acute lung injury. Am J Respir Crit Care Med 2008, 178:618623. 